\title{
EL DIBUJO COMO HERRAMIENTA PARA LA EDUCACIÓN EN SALUD ${ }^{1}$ THE DRAWING AS A TOOL FOR HEALTH EDUCATION O DESENHO COMO FERRAMENTA PARA A EDUCAÇÃO EM SAÚDE
}

\section{Daniel Gonzalo Eslava Albarracín ${ }^{2}$}

ALBARRACÍN, D. G. E. El dibujo como herramienta para la educación en salud Revista Eletrônica de Enfermagem (online), Goiânia, v. 4, n.1, p. 03-11. 2002. Disponível em http://www.fen.ufg.br.

\section{EL DIBUJO COMO HERRAMIENTA PARA LA EDUCACIÓN EN SALUD}

RESUMEN: A partir de la construcción de una metáfora, el autor desarrolla una reflexión entorno a la importancia de valorizar el dibujo como una herramienta importante para el mejor conocimiento del sentir, el pensar y el hacer de las comunidades rurales, con el objetivo de realizar un trabajo de educación y promoción de la salud más coherente con la realidad que estas comunidades viven. Se hace un breve recorrido histórico que articula el dibujo y su importancia en la generación de conocimientos como herramienta de comunicación y se formulan interrogantes en relación con el lenguaje de las imágenes y la necesidad de su mejor comprensión.. Por último, con base en la especificidad que caracteriza los mensajes en salud, se hace una reflexión critica orientada hacia la necesidad de utilizar el dibujo como una herramienta que permite el dialogo de saberes, como una fuente de aprendizaje que permite un mejor conocimiento de las necesidades y expectativas que en relación con la salud tienen las comunidades campesinas en las que continuamente se realizan actividades de promoción y prevención, eminentemente verticales y fuera del contexto de realidad en el que se desarrollan dichas comunidades.

SUMMARY: Starting from the construction of a metaphor, the author develops a reflection environment to the importance of valorizing the drawing like an important tool for the best knowledge of feeling, the to think and making of the rural communities, with the objective of carrying out an education work and promotion of the most coherent health with the reality that these communities live. A brief historical journey is made that it articulates the drawing and its importance in the generation of knowledge like communication tool and queries are formulated in connection with the language of the images and the necessity of its best understanding.. lastly, with base in the specificity that characterizes the messages in health, a reflection is made it criticizes guided toward the necessity of using the drawing like a tool that it allows the I dialogue of knowledge, like a learning source that allows a better knowledge of the necessities and expectations that have the rural communities in those in connection with the health that continually are carried out promotion activities and prevention, eminently vertical and outside of the context of reality that this communities are developed.

RESUMO: Com base na construção de uma metáfora, o autor faz uma reflexão em torno da importância da valorização do desenho como ferramenta para o melhor conhecimento do sentir, do pensar e do fazer nas populações rurais, visando um trabalho de educação e promoção da saúde mais coerente com a realidade que estas comunidades vivenciam. Com um breve percurso histórico se faz uma articulação entre o desenho e a geração de conhecimentos enquanto ferramenta de comunicação, levantam-se questionamentos relativos à linguagem das imagens e à necessidade da sua melhor compreensão. Finalmente, baseados na especificidade própria das mensagens em saúde, se faz uma reflexão crítica da visando a necessidade de utilização do desenho como subsidio para facilitar o dialogo de saberes, como fonte de aprendizagem que permite o melhor conhecimento das necessidades e expectativas de saúde das populações camponesas, comunidades estas, nas que continuamente são realizadas atividades de promoção e prevenção, eminentemente verticais e fora do contexto de realidade no qual elas vivem.

\footnotetext{
${ }^{1}$ Los conceptos aquí contenidos son fruto de la experiencia de trabajo en Educación para la salud con comunidades rurales campesinas, durante un periodo aproximado de 10 años y dentro del proceso de formación de estudiantes de enfermería, a través de la participación en planes, programas y campañas educativas.

${ }^{2}$ Enfermero Profesional, Profesor Asistente, Facultad de Enfermería, Universidad Javeriana. COLOMBIA. Especialista en Docencia Universitaria, Master en Administración en Salud, Master en Desarrollo Rural,
} 
A MANERA DE PRÓLOGO

\begin{abstract}
"La educación no puede modificar muchas condiciones objetivas, pero si puede conseguir mudar la manera como los individuos encaran las condiciones objetivas"
\end{abstract}

He querido comenzar estas reflexiones, pensando en una metáfora que me permita explicar al lector el eje central de mi exposición. Así pues, quienes de una $u$ otra forma hemos trabajado en programas, acciones o campañas de educación para la salud, no podemos negar que en algún momento nos hemos sentido como "socorristas".

Metafóricamente hablando, la visión y la actuación de los educadores en salud, como sujetos y como objetos de nuestro quehacer, es la de "salvavidas", que esperando en las márgenes de un caudaloso río, intentamos rescatar a las personas arrastradas por la corriente y evitar así que se ahoguen. Constantemente hemos visto como, algunas personas son rescatadas, otras quedan mal heridas y algunas infelizmente mueren. Lo curioso, es que existe un gran contingente de personas que, tras ser salvadas, al cabo de un tiempo las volvemos a ver nuevamente arrastradas por la corriente.

Así, la historia se repite una y otra vez. Por lo tanto, nos preocupamos cada día más por aprender las últimas técnicas de salvamento y realizar rescates cada vez mejores, olvidando que deberíamos ir río arriba para averiguar qué es lo que pasa, es decir, saber si las personas se caen, se tiran o es que están siendo empujadas.

Con esta metáfora pretendo resaltar la necesidad de reconocer que, a través de acciones simples podemos olvidar nuestras actitudes pasivas; que como profesionales de la salud, despojados de los títulos de "expertos", debemos ir río arriba para conocer que es lo que está sucediendo, acercarnos a esa realidad para comprender las circunstancias por las cuales algunos se arrojan al río, intentar evitar que caigan los que se caen; y buscar los medios para que los otros no sean empujados.

En este sentido, la educación para la salud se debe ver como uno de los múltiples caminos para llegar a la solución, para comprender hasta las más escondidas razones del porque la gente cae al río, sin olvidar que en la gran mayoría de las oportunidades, para esa misma gente, la enfermedad inclusive puede ser una travesía necesaria.

Muchas veces, quienes trabajamos en educación, percibimos con tanta claridad la importancia de los mensajes de salud que al comunicarlos a las personas damos por entendido que van a generar interés y que con estos mensajes las personas con seguridad podrán cambiar muchos de sus comportamientos. Desafortunadamente, tanto como educadores en salud y como simples "salvavidas" olvidamos que la comunicación no es sólo trasmitir sino compartir un mensaje.

Pensamos que comunicar en salud, es elaborar el mensaje pensando en la persona con la que nos comunicamos y no sólo pensando en lo que nosotros queremos decir. Es considerar todas las percepciones que tiene el otro y que de alguna manera influyen en su percepción acerca de lo que se le está hablando.

En esta perspectiva, mi propuesta es mostrar la importancia del dibujo como una de las formas de comunicación, -la comunicación visual-, en el proceso de compartir la información en salud que consideramos importante para determinado tipo de situaciones y comunidades.

\section{ARQUEOLOGÍA DEL DIBUJO Y DEL CONOCIMIENTO}

\section{Un breve e incompleto recorrido histórico ${ }^{3}$}

Junto con los gestos y la voz, el dibujo es uno de los lenguajes más antiguo y universal, mediante él podemos expresar y describir imágenes del mundo que nos rodea, explicar sus formas y hasta realizar asociaciones.

El dibujo ha venido considerándose tradicionalmente como instrumento de perfeccionamiento del trabajo de pintores $y$ escultores, teniendo lugar su aprendizaje en la Academia y en el taller. Aun así, debemos reconocer que cada uno de nosotros está en capacidad de dibujar, pues para dibujar, primero se leen las formas y luego se describen. Este es un ejercicio expresivo, que puede llegar a dominarse tras un período de aprendizaje y práctica, educa la inteligencia hasta el punto de que el dibujante sin necesidad de ser un artista puede ser capaz de mostrar a través del dibujo una forma de expresión abstracta.

Así, el dibujo es una herramienta de comunicación importante porque permita la manifestación sensible de una idea. La tarea de representar el entorno y los objetos, o de recrearlos y establecer asociaciones nuevas, que es en ultima instancia la esencia del dibujo, es una actividad

\footnotetext{
${ }^{3}$ Breve e incompleto en la medida en que el Autor no tiene la disponibilidad de espacio suficiente para hacer un recorrido profundo y detallado a través de la historiografia de las expresiones artisticas, además de no ser ese el objetivo principal del trabajo. Aun así, es necesario recurrir a la historia, a algunos antecedentes para contextualizar el tema y entender como, a través de los diferentes momentos históricos, el dibujo aparece como una forma concreta de representar las características propias de la época.
} 
noble que debe ser valorada por su utilidad para facilitar la comunicación entre quienes tenemos grandes brechas educativas, sociales y culturales.

Desde las cuevas del paleolítico, hasta los abrigos rupestres, el dibujo aparece como lenguaje de comunicación de acontecimientos mágicos, como motivo ornamental, o inclusive con carácter no figurativo, en forma de pictografía aún por descifrar; estos dibujos denotan un alto grado de complejidad y demuestran que el arte del dibujo estaba ya desarrollado en la época prehistórica.

En el antiguo Egipto se utilizaban como modelos para la pintura y la escultura dibujos a tinta sobre papiros y fragmentos de vasijas incisos con figuras y motivos, como ocurría en Mesopotamia con los dibujos tallados en tablillas de arcilla. Estos dibujos, marcados en un principio por la estricta representación frontal y la exageración de las formas, fueron dejando paso a un mayor naturalismo, como en el arte de los reinados de Ajnatón en Egipto y de Assurbanipal en Asiria .

En el transcurso de los siglos, griegos y romanos impulsaron las artes de la pintura $y$ escultura, supeditadas ambas siempre a la teoría inexcusable del dibujo. Unos cuantos dibujos preparatorios de origen griego y romano han llegado hasta nosotros, sobre tabla, pergamino, metal, piedra o marfil. Los dibujos terminados, tal como se ven en las vasijas griegas, indican la evolución desde el arcaísmo estilizado a la idealización clásica de la naturaleza, e incluso al tratamiento naturalista de la forma humana. En cuanto al dibujo romano, era en general realista, si bien continuaba mostrando influencias griegas.

En los monasterios de la Europa medieval, los textos religiosos eran inscritos en pergamino, y después embellecidos con iniciales, Márgenes decorados y escenas resaltadas. En la Europa románica, se utilizaban los dibujos como modelo en la mencionada iluminación de manuscritos y también corno cartones o estudios, para frescos, esculturas, y otras modalidades artísticas.

Durante el renacimiento, el redescubrimiento humanista del clasicismo grecorromano, la invención de la imprenta y la gran variedad de papeles y de utensilios disponibles, impulsaron el desarrollo del arte del dibujo. Ya sea Como estudios preparatorios para pinturas o esculturas o, por primera vez en Occidente, como obras de arte independientes, las obras maestras del dibujo de los artistas renacentistas revelan comprensión de las formas naturales y su idealización.

Los dibujos del siglo XVII tienden a expresar un dramatismo y una energía de corte barrocos, en contraste con el apacible orden arquitectónico de la época. Los dibujos del siglo XVIII, típicos del estilo rococó, con un enfoque neoclásico muestran figuras realizadas con gran fuerza que contrastan con los dibujos discretos y realistas de temas cotidianos que satirizaban la guerra y la injusticia.

El creciente ritmo de cambio político y económico de la época moderna quedó reflejado en la gran variedad de estilos artísticos tales como el neoclasicismo resurgente de las tensas figuras lineales $\mathrm{y}$ de los retratos, el romanticismo representado en las tonalidades de los dibujos y el realismo un tanto agresivo de numerosas caricaturas satíricas.

En el siglo $X X$ el dibujo tiende a ser constructivista aunque más abstracto. El surrealismo francés y el expresionismo estadounidense inspiraron dibujos más abiertos y espontáneos. También se empezaron a explorar la textura, las escalas, al tiempo que continuaba el interés por los dibujos de contorno tradicionales.

Ahora en la actualidad, comenzando el siglo XXI y ante la supremacía de los medios electrónicos de comunicación, el dibujo tiende a ser reemplazado por una gran diversidad de formas y expresiones gráficas, que desde la óptica contemporánea se describen como "disciplinadoras" de la población, en la medida en que van transformando la definición de los espacios urbanos y transforman la división tradicional entre espacio público y espacio privado.

\section{Dibujo y conocimiento}

Recurramos a los descubrimientos de los Arqueólogos y Paleontólogos, ubiquémonos unos treinta mil años atrás, en el interior de una caverna, observamos varios adolescentes temblando en la oscuridad, están esperando una iniciación al culto de los hacedores de herramientas, las semanas de ayuno y abstinencia, las pruebas de silencio y sufrimiento, los rituales de toque de tambor, cantos y danzas están a punto de alcanzar el clímax.

Una vez al año, los candidatos que han cumplido cierta edad son llevados al interior de las cavernas por un grupo de fabricantes de herramientas, chamanes y artistas cuyas actividades cambiaban el modo en que la raza humana trabajaba y vivía.

Luego de recorrer pasillos oscuros, estrechos, profundos, se llega a cámaras especiales. Después de los cánticos, los mitos y textos susurrados, la oscuridad es rota por antorchas y lámparas dispuestas a intervalos estratégicos. Los jóvenes que están situados en posiciones predeterminadas con exactitud, ven de pronto figuras sobrenaturales que flotan en el espacio delante de ellos: bisontes, pájaros, símbolos, figuras humanas que saltan desde la oscuridad llenando su campo de visión.

En este momento de miedo y temblor inducido audiovisualmente, se imparten los primeros secretos "tecnológicos". La mente sensibilizada de los iniciados, se marca con secuencias elaboradas de visiones y sonidos. Los conocimientos, la 
información, son grabados en los cerebros de nuestros ancestros con el acompañamiento de un espectáculo tridimensional de luz y sonido. ${ }^{4}$

Esta pequeña historia permite comprender como, en la época en que se crearon las pinturas rupestres, nació una nueva forma de vida. Se fueron produciendo cambios en casi todos los campos del entendimiento humano. Muchas de las pinturas de estas cavernas son figuras distorsionadas sobre protuberancias y depresiones naturales en la piedra caliza, a fin de que las representaciones tuvieran una apariencia tridimensional al ser vistas bajo una luz y un ángulo adecuados.

Otras imágenes fueron talladas en la pared de modo que solo se vieran cuando se movía una luz que incidía en ellas desde un ángulo apropiado. Todo esto se podría deber a la intención de crear un "estado de conciencia alterado" para favorecer la impresión de información en la mente de nuestros ancestros, así se llevaba a cabo el aprendizaje.

El aprendizaje de hoy es el resultado de la elaboración creciente y en mayor escala, de las fuerzas liberadas miles de años atrás durante el paleolítico superior.

La tarea de procesar y analizar la información es aún decisiva, la tarea de la comunicación es crear símbolos más compactos, nuevos, imágenes más refinadas sobre las pantallas de un televisor, una computadora, etc., para generar y difundir conocimiento.

La supervivencia sigue dependiendo del uso de todos los recursos, del arte y la ceremonia, así como de la tecnología, para construir sociedades "estables", organizadas a partir de una cantidad creciente de individuos desconfiados, temerosos e impredecibles que necesitan ser "disciplinados".

\section{COMUNICACIÓN, IMAGEN Y EDUCACIÓN}

La comunicación humana surgió en el momento en que nuestros ancestros en su lucha por la supervivencia y en respuesta a sus instintos se vieron obligados a transmitir a quienes les rodeaban, sus impresiones, sentimientos, emociones. Para ello se valieron de la mímica, de los gritos y las interjecciones, lo que constituyó un lenguaje biológico.

Posteriormente surgió el lenguaje hablado y las manifestaciones pictóricas. Aparecen las pinturas rupestres, los jeroglíficos; pudiendo así el hombre,

\footnotetext{
${ }^{4}$ La paleontología contemporánea argumenta que las actividades en aquellas cavernas estaban estrechamente relacionadas con una serie de cambios que se producian en el pensamiento y la acción humanos y que continúan reverberando hoy en día. Las cavernas y otros lugares similares podrían ser sitios donde se llevaba a cabo el aprendizaje.
}

por primera vez expresar su pensamiento de un modo gráfico.

El pensamiento humano ha evolucionado tornándose cada vez más complejo y ecléptico, acorde a este y como representación del mismo su expresión gráfica ha sufrido una evolución similar. Hemos pasado de las primeras figuras simples y esquemáticas que reproducían la realidad más cercana de sus artífices a las complejas composiciones de hoy, inspiradas en todo tipo de temas, asistidas por un sinfín de técnicas y distanciadas en muchos casos de lo conocido.

Hoy podemos hablar del lenguaje de las imágenes, de una semiótica de las imágenes, de sus mensajes, de su interpretación, de la imagen como información primordial y no secundaria. Ante estas evidencias, entendemos que la imagen tiene un papel primordial en los procesos comunicativos, más aun en los que tienen que ver con la educación en salud.

Así, valdría la pena que quienes hacemos parte de estos procesos nos preguntemos:

¿Sabemos leer las imágenes?

¿Somos conscientes de la importancia creciente de estas como transmisoras de la información?

¿El no saber interpretarlas puede considerarse analfabetísmo visual?

El rápido desarrollo de las técnicas de gráfica computarizada es parte de la reconfiguración de las relaciones entre una observación subjetiva y modos de representación que invalidan definitivamente la mayoría de los significados culturalmente establecidos para los términos observador y representación.

La difusión y la formalización de imágenes generadas por computadoras prometen la implantación omnipresente de "espacios" visuales fabricados. Pero espacios diametralmente distintos a los espacios miméticos como el cine la fotografía o la televisión.

Las técnicas (realidad virtual, ideografía dinámica, hipertextos, resonancia magnética, holografía, sensores multiespectrales, etc.) para la producción de imágenes están relocalizando la visión, la percepción, en un plano separado del observador humano. A la vez, estas técnicas se están convirtiendo en los modelos dominantes de visualización, de acuerdo a los cuales funcionan los procesos de orden social y las instituciones.

No es difícil darse cuenta que los profesionales de salud aplicamos estrategias y tácticas particulares de comunicación, para que los sujetos y las poblaciones adopten comportamientos deseados por nosotros y/o las instituciones que representamos, a través de diferentes mecanismos.

Así, en los interminables planes y programas de Educación para la salud el objetivo primordial es la modificación de hábitos y estilos de vida de las 
comunidades. Desafortunadamente, al implementar las diferentes estrategias educativas, "concientizadoras" olvidamos que en el proceso de adopción de comportamientos por parte del sujeto, las funciones del ojo humano tienen una función vital, no sin razón existe en el imaginario popular la afirmación de que "todo entra por los ojos"

Debemos recordar que hoy en día, las imágenes que antes para nosotros eran reales, vivas, veraces, están siendo suplantadas por técnicas en las cuales las imágenes visuales, ya no tienen ninguna referencia respecto de la posición de un observador en un mundo "real" y ópticamente perceptible, podríamos decir que hoy en día no sabemos si lo que vemos es realidad, es fantasía o es una "fantasía real".

Las imágenes que ahora vemos y por consiguiente, la información y el conocimiento que nos llega a través de ellas está situado en los terrenos de lo cibernético, electromagnético, donde la abstracción visual y los elementos lingüísticos se entremezclan y coinciden, se consumen e intercambian en el ámbito de lo que algunos llaman "el conocimiento global".

Estamos ante un proceso por el cual se desarraiga y hace móvil lo que esta fijo, se despeja o destruye lo que impide la circulación, y se hace intercambiable lo que es singular. Todo esto es lo que sucede en este proceso de modernización, donde el sujeto humano se constituye o se lo constituye de acuerdo a los nuevos acontecimientos, fuerzas e instituciones y regímenes de visibilidad.

Las sociedades controlan a la población por medio de la "gigantesca maquinaría de instituciones (familia, medios de comunicación, la escuela, centros de trabajo, clubes sociales y deportivos, partidos políticos, etc.) que encuadran a los individuos a lo largo de su existencia" y de acuerdo con practicas disciplinarias tendientes a ordenar, clasificar y constituir los cuerpos de los sujetos, sus posiciones y desplazamientos de los espacios íntimos, en los espacios privados y en los espacios públicos.

\section{LA IMAGEN Y LA EDUCACIÓN EN SALUD}

La imagen constituye un fenómeno de transmisión y recepción de conocimiento que responde a una forma de pensamiento autónomo. A lo largo de la historia, la imagen ha desempeñado una función de transmisión de conocimiento desde un plano cognoscitivo.

A medida que sus modalidades expresivas proliferan (desde la imagen fija hasta la secuencial en movimiento) la complejidad en la comprensión de sus mensajes aumenta y a medida que su presencia es mayor, la necesidad de interpretar sus significados reales aumenta también. Conocer su lenguaje (gramática y sintaxis), desentrañar sus significados, estudiar sus mensajes explícitos y ocultos, es cada día una necesidad mayor.

Los procesos para desarrollar conceptos gráficos y plasmarlos de una forma gráfica (repetible, codificable, distribuible, perdurable, etc) se ejecutan desde una serie de funciones complejas que están cargadas de características que provienen de la forma concreta en que las personas que las realizan viven y piensan. Este interesante contenido gráfico es poco evidente a primera vista ya que cada observador verá cualquier imagen partiendo de su propia codificación aprendida durante su particular desarrollo como persona perteneciente a un colectivo y momento concreto.

Existe una capacidad representacional que es común a todo hombre, independientemente del tiempo y sociedad en que viva. Esta capacidad le sirve como base desde la que construir su clave específica de formación de imágenes gráficas a plasmar, quedando modificadas aquellas que le son propias a su condición de ser humano. Esta transformación se opera en función de las condiciones que le son propias al vivir un momento concreto y en un tiempo específico".

Para desentrañar una información gráfica es necesario, además del entendimiento del terreno perceptivo que es común a todo ser humano, interpretar correctamente su contenido por medio del conocimiento de aquellas claves concretas con que el productor de la imagen la construyó. Todo esto es posible hacerlo si entendemos bien aquellas características precisas del proceso perceptivo y del proceso particular en que se realiza una imagen. Además, habrán de tenerse en cuenta aquellas características gráficas que resultan de la capacidad creativa del individuo concreto que produce la imagen. Por lo general las imágenes se construyen desde una sintaxis que viene determinada por un momento histórico-temporal concreto y un área social y geográfica particular, desde los cuales se establece un estilo y sintaxis común, donde la participación del individuo suele ser meramente causal

Estos planteamientos me permiten asegurar que antes de elaborar un mensaje de salud, es muy útil por no decir imprescindible, formularnos las siguientes preguntas

¿Cómo percibe el tema mi interlocutor?

¿Qué palabras usa para el tema?

¿Cómo influyen sus creencias en su comprensión del mensaje?

¿Qué momento psicológico está pasando esa persona?

¿Cómo su condición de género (hombre o mujer) influyen en el modo de percibir el mensaje?

¿Cómo su pertenencia a un grupo étnico influyen en la percepción de mi mensaje?

Debemos reconocer que no es fácil tratar de incluir estos aspectos en el momento que elaboramos nuestro mensaje de salud, aun así, el solo hecho de intentar hacer este ejercicio puede 
aumentar nuestras posibilidades de ser comprendidos y de persuadir con lo que decimos. Por otra parte, no podemos olvidar que ante nuestros receptores, el personal de salud tiene un estatus de autoridad, por lo tanto, nuestros mensajes tienen cierta veracidad ganada de antemano por nuestra condición.

Así, comunicar salud sigue siendo un desafío con características propias que no tienen otros mensajes. Veamos algunas de las características más comunes que desde mi experiencia personal hemos encontrado en el desarrollo de campañas, programas e inclusive materiales oficiales para la educación en salud.

- Complejidad: Los mensajes de salud son muchas veces complejos, es así como mensajes aparentemente sencillos conllevan toda una carga ideológica y representacional que acaban quedando lejos de la verdadera intensión educativa $y / o$ informativa que persiguen:

Ejemplo: Para toda la población hemos estructurado un programa orientado a establecer un sistema descentralizado de suministro de medicamentos para el primer nivel de Atención que, bajo los principios de equidad $y$ eficiencia, garanticen a la población el acceso a los medicamentos esenciales de calidad a bajo precio".

Otros que a pesar de su pequeño tamaño y escaso contenido conllevan toda una explicación sobre el tema de interés, pero al mismo tiempo su interpretación puede ser tan amplia, que terminan por producir un mensaje vago y carente de sentido.

\section{Ejemplo: "La solución contra el cólera está} en tus manos"

- Relatividad: En algunos mensajes que se difunden pueden haber opiniones distintas sobre un mismo tema, a pesar de la importancia del mismo, las afirmaciones que se hacen se dan por ciertas y absolutas sin reconocer que existe la posibilidad de que las mismas generen controversia en los receptores.

Ejemplo: "La ligadura de trompas es un método de control de la natalidad totalmente irreversible" "Las píldoras anticonceptivas son el método de planificación más seguro"

- Cientificidad: Estamos acostumbrados a usar palabras difíciles y/o términos demasiado técnicos que no permiten que el mensaje sea entendido por la mayoría de las personas.

Ejemplo:

"Su hijo está sumamente diaforético"

"Su hematúria se debe a una litiásis renal"

- Dualidad: Muchas veces ante una misma información existen posiciones opuestas que se convierten en mutuamente excluyentes, lo que lleva al receptor a un estado de incredulidad frente a los mensajes que recibe. Así vemos como en algunos mensajes sencillos de salud pueden haber versiones que se contradicen

Ejemplo: "Es necesario comer mucha carne de todo tipo porque contienen proteínas indispensables para nuestra salud"

"La carne tiene muchas toxinas, es dañina para la salud, yo recomiendo suplantarla con otros alimentos igual de nutritivos"

Aparte de estas características, quienes producimos mensajes en salud no podemos olvidar que la información constantemente está cambiando y que no somos nosotros los únicos que la poseemos. Hoy en día los medios masivos de comunicación están a disposición de casi la totalidad de la población y a través de ellos también se pasan un sinnúmero de mensajes que de alguna manera también conllevan las características anteriormente descritas.

Otro elemento importante para tener en cuenta es que la salud (por lo menos en nuestra realidad latinoamericana) aún es un tema que llama mucho la atención de la población, y que a veces el afán por obtener mayor conocimiento se debe en cierta medida al miedo particular que muchos tenemos a la enfermedad y por consiguiente a la perspectiva de la muerte que ésta conlleva.

\section{LA IMPORTANCIA DEL DIBUJO}

No podríamos hablar del dibujo sin reflexionar antes en algunas de las definiciones que se han elaborado de ésta palabra. Tal vez una de las más bellas sea la definición dada por Leonardo da Vinci, para él "el dibujo era una deidad a través de la cual se creaba un mundo de la misma manera en que lo hizo Dios".

En esta definición llama la atención la cuestión de la creatividad, es decir la capacidad de los individuos para crear, en nuestra experiencia de trabajo en comunidades rurales campesinas, esta

${ }^{5}$ ESTEVA-GRILLET, R. El dibujo en Venezuela: Estudio y antología de textos. Fundarte. Alcaldía de Caracas. 1992: p.35) 
capacidad la hemos entendido como la posibilidad de re-crear, de permitir que el receptor, a través de las imágenes que ve, tenga la posibilidad de hacerse una idea propia de aquello que el dibujo en sí le está transmitiendo.

Así, entendemos que a través de los dibujos, los educadores en salud podemos objetivar la representación más inmediata que tienen las personas de su realidad en una superficie que es visible a todos y sobre la cual todos estamos en la mismas posibilidades de discutir, analizar, criticar y construir.

Lo anterior sugiere que a través de los dibujos, los mensajes en salud pueden disminuir de manera considerable los problemas de complejidad, relatividad, cientificidad y dualidad que los caracterizan.

En nuestras experiencias particulares de procesos educativos para la salud de las comunidades rurales, cometimos muchas veces el error de pensar que hablábamos de comunicación cuando nos referíamos a campañas, o a materiales educativos. Sin embargo luego de mucho aprender fuimos conscientes que todo el tiempo nos estabamos comunicando. Así, como personal de salud siempre fuimos foco de atención ante la población.

Aprendimos que con frecuencia los médicos, enfermeras, técnicos y promotores son observados por la comunidad más de lo que ellos mismos se lo imaginan, pudimos constatar que muchas de las personas de las comunidades en las que trabajamos fueron capaces de describir con detalle los hábitos y las costumbres del personal de salud y hasta llegaron a decirnos que no éramos consecuentes en lo que decíamos y en la forma como actuábamos, en palabras de la comunidad "el cura predica pero no aplica"

En términos de comunicación, otro error que cometimos fue el de creer que por el hecho de hablar de maneras diferentes podía darse un proceso de comunicación efectivo, aprendimos lo equivocados que estabamos, cuando percibimos la sensibilidad de los campesinos ante cosas tan simples como el tono de nuestra voz durante las charlas, la forma de vestirnos para asistir a las reuniones, los gestos que hacíamos cuando nos invitaban a comer, en fin, como ellos, más que nosotros, percibían con mayor facilidad algunos de los signos más evidentes de lo que llamamos comunicación no verbal y que están muy por encima de las condiciones educativas, sociales, culturales y hasta económicas de la población y sus interlocutores del sector salud.

Así, aprendimos que existen otra serie de actitudes que resultan sumamente elocuentes y que dan paso a una buena comunicación. Dentro de muchas otras percibimos cuan importante es para el campesino demostrarle que el equipo de salud en realidad se interesa por él, es decir, que su condición como persona está por encima de su situación de salud o de las características de su enfermedad. En este sentido compartir con el sus actividades de la vida cotidiana, sus preocupaciones y sus alegrías, garantizaba una mejor comunicación y entendimiento entre los actores del proceso comunicativo.

Cuando hablamos de "educar a las personas" olvidamos que éstas tienen sus propias creencias, sus propias formas de ver y entender el mundo que las rodea, ellos muchas veces asistían a las charlas creyendo que sus problemas de salud se debían a determinadas causas y que la mejor manera de solucionarlos era la que ellos pensaban y luego a pesar de toda la información y "educación impartida por nosotros, salían convencidas de lo mismo.

Estas experiencias llenas de aciertos y desaciertos, pero sobre todo de continuos aprendizajes nos llevaron a pensar la posibilidad de hacer procesos educativos en doble vía, es decir, hacer que fuesen las propias comunidades las que nos contaran, nos hablaran y nos enseñaran todo aquello que ellas consideraban que nosotros como agentes de salud debíamos aprender. Es en este sentido, en el que encontramos realmente la importancia del dibujo para "comunicar salud", pues si recordamos la metáfora que leímos al comienzo de estas páginas, por fin los socorristas entendimos que debíamos ir río arriba para ver que era lo que estaba pasando, es decir, quisimos ir a entender porque se ahogaba la gente.

Pasamos de profesores a aprendices, dejamos que fuera la propia comunidad la que nos indicara que caminos deberíamos tomar si realmente queríamos no solo enseñarles algo, si no también aprender con ellos. Es en este momento en que por iniciativa de la propia comunidad surge el dibujo (dentro de algunas otras posibilidades) como una herramienta que nos permitiría acercarnos a su realidad y poder así entenderla para tratar de intervenir en ella de manera conjunta.

\section{EL DIBUJO COMO FUENTE DE APRENDIZAJE}

Para nosotros, haber subido por la margen del río a conocer las razones por las cuales las personas estaban cayendo en él, significó una experiencia de aprendizaje recíproco que nos ayudó no solo a conocer mejor una realidad por nosotros desconocida, si no también, la posibilidad de interactuar de manera conjunta con los campesinos en su realidad, con el objetivo de intervenir mejor en ella y de manera conjunta contribuir para modificarla.

Así, encontramos en el dibujo una de las mejores herramientas para que ellos nos expresaran sus necesidades, sus problemas y al mismo tiempo sus alternativas de solución. Descubrimos allí un mundo nuevo para nosotros, un mundo en el cual la 
creatividad y habilidad para plasmar las ideas en una superficie plana en realidad nos sorprendieron.

Los campesinos, niños, adultos hombres y mujeres consiguieron a través de sus dibujos enseñarnos nuevas cosas y hacernos reflexionar de manera profunda acerca de nuestra práctica educativa. Intentaremos de manera resumida compartir con el lector algunos de los elementos de reflexión que conseguimos construir con base en esta experiencia mutua y participativa de trabajo comunitario.

\section{Dibujo e lgnorancia}

Comúnmente los trabajadores de salud llegamos a las comunidades con la premisa de que las comunidades rurales, por el hecho de estar alejadas de los grandes centros urbanos y en sí, de los avances de la información y la tecnología, son comunidades que en general "no saben". Desde ésta perspectiva -que de alguna manera era la nuestra- la educación se entiende como un proceso para transmitir información y llenar con ésta el vacío de conocimientos que tiene las personas. Desde allí, hay aun quienes en la práctica educativa consideran la ignorancia como una de las principales características de los grupos a los que "hay que educar".

Estas concepciones aún se perciben en infinidad de estudios y procesos que pretenden bajo el lema de trabajos comunitarios, participativosidentificar las creencias, actitudes y practicas de las personas, pues consideran igualmente que la acción de los individuos derivan de su ausencia de conocimientos. Lo anterior sugeriría que un aumento en los conocimientos, genera un cambio en las actitudes y por lo tanto se modifican las prácticas, lo cual es en últimas el objetivo central de las acciones de educación en salud.

Desde nuestra experiencia, los campesinos con sus dibujos nos enseñaron que en su cotidiano, esta lógica no funciona así. Ellos actúan por causas mucho mas complejas que la simple información. Los individuos que en un principio nosotros presumimos como ignorantes, tienen muchos conocimientos, muchas creencias, opiniones y saberes que nosotros no podemos considerar como "malas, equivocadas o incorrectas". Debemos reconocer que son estas ideas las que conforman su saber y que es precisamente ese saber el que guía sus conocimientos.

Por lo tanto, para nosotros una primera y gran enseñanza fue la de entender que, hablando de educación para la salud, el objetivo de nuestra acción no debe ser el de llenar con nuestros conocimientos el vacío de la ignorancia, pues eso sería no reconocer en el otro su capacidad para aprender y reflexionar. Nuestra acción educativa debe por el contrario, valorar los saberes, las ideas, los hábitos de la población que es sujeto de nuestra acción, pues ante todo la labor educativa debe ser recíproca, respetuosa y sobretodo, solidaria.

\section{Dibujo como fuente para dialogar}

En esta secuencia reflexiva, asumimos que tanto los campesinos como los agentes de salud conocemos algo sobre el mundo, unos con determinado grado de profundidad, sin importar si es mayor o menor, pero en el sentido estricto de la palabras, no somos por completo ignorantes.

Si asumimos entonces la premisa de que no es que uno sepa más que otro, si no que ambos sabemos cosas distintas, entenderemos el porque del lógico reclamo de los campesinos al pedir que los tratáramos de igual a igual, es decir como personas que quieren aprender, pero también tienen algo que enseñar. Era lógico, a pesar de que el campesino no sabe ni ha estudiado nada sobre "entomología", toda su vida ha ido recopilando información acerca de los insectos, probablemente el pueda describir y explicar mejor que en los libros el porque de determinado proceso o conducta en un insecto en particular. Entonces, por que no se les pregunta?, por que no se les pide su opinión?.

Los dibujos de los campesinos nos permitieron aprender, que la actividad de educación en salud debe ser un proceso de dialogo en el que ambas partes se comprometen a escucharse y a transformarse, un proceso en el que todos actuamos por igual a pesar de que mantengamos roles diferenciados. Desde nuestra perspectiva modificada ahora por nuestra experiencia de trabajo en las comunidades campesinas- la actividad educativa debe garantizar la confrontación de perspectivas y prioridades, pues son tanto las del agente de salud, como las de la comunidad son validas, legítimas e interesantes.

Aprendimos que en el proceso educativo para la salud, nadie manda ni nadie obedece, todos construyen, esto significa que todos diseñamos determinada estrategia para enseñar y todos nos comprometemos a aplicar lo que aprendimos. En ultimas, lo que se persigue es que a través de la acción educativa, todos consigamos dialogar para intercambiar conocimientos, olvidando actitudes de dominación y sometimiento.

\section{A MANERA DE CONCLUSIÓN}

Nuestra experiencia de trabajo y el constante enfrentamiento con las ideas y los saberes campesinos expresados a través de las más diversas formas de expresión verbal y no verbal, nos han llevado a re-hacer nuestros conceptos y nuestras acciones entorno a lo que se denomina "Educación en salud". Hoy en día, luego de mucho ir y volver a lo largo del río de nuestra metáfora inicial, hemos comprendido que el proceso de enseñanza-aprendizaje relacionado con la salud, sea en la escuela académica o en la vida cotidiana, 
debe ser asumido como una tarea mucho más compleja y profesional de lo que muchos hemos pensado.

Necesitamos investigar más y convivir más para obtener unas bases fuertes que nos permitan salir del arcaico método de ensayo y error con el que hemos venido asumiendo la práctica educativa, pues como bien nos enseñaron los campesinos, la adquisición de conocimientos, los cambios conceptuales y los comportamientos de los individuos no dependen solamente de la información que se les proporcione.

Por otra parte, quienes pretendemos seguir trabajando para "educar en salud" debemos luchar para superar ese carácter dogmático y autoritario con el que muchas veces asumimos la actividad educativa. Debemos entender que si realmente queremos educar en salud, no podemos pretender continuar con la idea de que la mejor manera para hacerlo es substituir algunos dogmas y reglas que nosotros imaginamos "equivocados" por lo que a nuestro juicio son correctos.

Pensamos que a través de la acción educativa, debemos hacer posible que los individuos que son sujeto de nuestra acción desarrollen los conocimientos que les permitan buscar otros nuevos, para que ellos mismos sean capases de escoger los comportamientos y los caminos que quieren seguir.

Así, consideramos que intentar comprender el pensamiento, los sentimientos y las ideas de quienes están "siendo educados", en nuestro caso, a través de la expresión gráfica de sus ideas, es una posibilidad rica -dentro de muchas otras- de aprender junto con ellos. Dibujar no solo es para que el niño se distraiga, pues el dibujo permite la expresión libre y espontánea de la visión que el individuo tiene de las cosas y en general del mundo que lo rodea, inclusive de aquellos que de manera equivocada juzgamos como ignorantes.

Algo que nos ha preocupado a lo largo del camino que hemos recorrido en el proceso de intentar "educar en salud" es lo que hemos visto de manera frecuente en el cotidiano de las personas, independientemente de si son letradas o iletradas. Nos referimos en el caso de nuestra metáfora al hecho de que a pesar de haber ido a la comunidad a conocer y entender porque se arrojan al río, y haber realizado todo un proceso comunicativo $y$ participativo del cual salen alternativas para no continuar con esa práctica, muchos de los que asistieron y participaron en el proceso, aun se siguen arrojando.

Nos parece que a pesar de todos nuestros esfuerzos, nuestros aprendizajes y nuestros avances, aún no hemos conseguido los frutos esperados, es decir, nos parece que nuestra actividad educativa en salud aún es frágil, nos sentimos frustrados porque a pesar de haber conseguido cambios significativos en la manera como los campesinos encaren sus problemas de salud, sus prácticas concretas no reflejan los logros que pensamos haber obtenido. ${ }^{6}$

A pesar de nuestra frustración el resultado es lógico, pues sabemos que con educación no se pueden superar muchas de las condiciones objetivas que están asociadas a las precarias condiciones de salud de nuestras poblaciones marginales (urbanas y rurales), sabemos que con educación no generamos empleo, con educación no mejoramos los ingresos familiares ni el acceso a los servicios de salud, por el contrario, algunas veces hasta los limitamos muchos más.

Finalmente, somos consientes de que se requiere mejorar cada vez más la formación en técnicas educativas, aun así creemos que eso no es todo, los dibujos de los campesinos nos muestran cosas importantes, nos ratifican que en el proceso educativo todos somos responsables y que de la misma manera como la salud es demasiado importante para dejarla en manos de los médicos, la educación es demasiado importante para que quede solo en manos de los educadores, pues la educación y dentro de esta, la educación en salud, es un hecho y una responsabilidad de todos.

Nuestro proceso nos ha enseñado que para muchos la investigación es un lujo, aún para la academia la investigación que se hace responde más a modas o políticas de desarrollo tecnológico, donde el análisis de la realidad, así sea través de simples dibujos no tiene ninguna importancia. Pensamos que a través de esa expresión libre, voluntaria y transparente de las necesidades reales de una población, se hacen evidente lo limitado de nuestro conocimiento $y$ lo infinito de nuestra ignorancia en relación con lo que otros piensan y sienten frente a la manera de cuidar su salud.

El dibujo como eventual fuente de conocimiento e información, puede evidenciar los conocimientos, los saberes y la conciencia que tienen los individuos sobre la realidad social. A través de su interpretación, los que aun piensan en la educación en salud como una "misión salvadora" no verán nunca la importancia que puede tener para el futuro de una población, los simples trazos hechos por un campesino intentando explicar lo que para el significa estar sano o tener salud.

Los que de alguna manera ya iniciamos ese largo y rico camino de la interpretación, entendemos que hoy en día la educación en salud es una

${ }^{6}$ En este sentido recordamos personaje de un cuento popular que realiza psicoanálisis durante 10 años para dejar de orinarse en la cama, solo que al final del tratamiento continua orinándose pero ahora con la diferencia de que ya sabe porque y tiene un arsenal incalculable de técnicas para solucionar su problema. 
contribución, un paso más en un largo camino hacia la búsqueda de una mejor destino común. En ese sentido, el dibujo es para nosotros una excelente herramienta para la comunicación, un espacio de iguales, un espacio donde la creatividad y la imaginación surgen como verdaderas estrategias para el cambio y el mejoramiento de realidades diversas y semejantes en la población.

\section{BIBLIOGRAFÍA CONSULTADA}

GADOTTI, M., A Educação Contra a Educação. Rio de Janeiro: Paz e Terra. 1982.

HUBLEY, J., Health education in developingb countries. The need for an appropriate technology. Health Education Research, 3: 387, $1988 .$.

MACALISTER, A. L.; PUSKA, P.; ORLANDI, M.; BYE, L. L. \& ZBYLOT, P. L., Behaviour modification: principles and illustrations. in: Oxford Textbooks of Public Health, 2nd. ed., vol. 3. Oxford: Oxford University Press. 1991.

MACDONALD, J. J. \& WARREN, W. G., Primary health care as an aducational process; a model and a Freirean perspective. International Quarterly of Community Health Education, 12:35, 1992.

RIFKIN, S. B. \& WALT, G., Why health improves: defining the issues concerning 'comprehensive primary health care' and 'selective primary health. Social Science and Medicine, 23:559-556. 1986.

ROSENSTOCK, I. M., The Past, Present, and Future of Health Education. In: Health Behavior and Health Education: Theory, research and practice (K. Glanz, F. M. Lewis, B. K. Rimer, eds.) pp. 405- 420. San Francisco: Jossey-Bass Inc. 1990.

ROZEMBERG B., A Intransparência da Comunicação: crítica teórico-metodológica sobre a interação do saber e das práticas médicas e a experiência das populações de área rural endêmica de esquistossomose. Rio de Janeiro: Tese de Doutorado, Escola Nacional de Saúde Pública/Fiocruz. 1995.

SCHALL, V. T., JURBERG, P.; BORUCHOVITCH, E.; FÉLIX-SOUSA, I. C.; ROZEMBERG, B. \& VASCONCELLOS, M. C., Health education for children: Developing a new strategy. Proceedings of the Second International Seminar on Misconceptions and Educational Strategies in Science and Mathematics.Vol. II. pp. 390-403. Nova York: Cornell University. 1987. 